\title{
Emerging Contributions of Solid-State NMR Spectroscopy to Chromatin Structural Biology
}

\author{
Bryce E. Ackermann and Galia T. Debelouchina* \\ Department of Chemistry and Biochemistry, University of California, San Diego, La Jolla, CA, United States
}

OPEN ACCESS

Edited by:

Loren B. Andreas,

Max Planck Institute for Biophysical

Chemistry, Germany

Reviewed by:

Christopher Jaroniec,

The Ohio State University,

United States

Lars Nordenskiöld

Nanyang Technological University,

Singapore

Xiangyan Shi,

Shenzhen MSU-BIT University, China,

in collaboration with reviewer $L N$

*Correspondence:

Galia T. Debelouchina

gdebelouchina@ucsd.edu

Specialty section:

This article was submitted to

Structural Biology,

a section of the journal

Frontiers in Molecular Biosciences

Received: 14 July 2021 Accepted: 20 September 2021

Published: 11 October 2021

Citation:

Ackermann BE and Debelouchina GT (2021) Emerging Contributions of Solid-State NMR Spectroscopy to

Chromatin Structural Biology.

Front. Mol. Biosci. 8:741581.

doi: 10.3389/fmolb.2021.741581
The eukaryotic genome is packaged into chromatin, a polymer of DNA and histone proteins that regulates gene expression and the spatial organization of nuclear content. The repetitive character of chromatin is diversified into rich layers of complexity that encompass DNA sequence, histone variants and post-translational modifications. Subtle molecular changes in these variables can often lead to global chromatin rearrangements that dictate entire gene programs with far reaching implications for development and disease. Decades of structural biology advances have revealed the complex relationship between chromatin structure, dynamics, interactions, and gene expression. Here, we focus on the emerging contributions of magic-angle spinning solid-state nuclear magnetic resonance spectroscopy (MAS NMR), a relative newcomer on the chromatin structural biology stage. Unique among structural biology techniques, MAS NMR is ideally suited to provide atomic level information regarding both the rigid and dynamic components of this complex and heterogenous biological polymer. In this review, we highlight the advantages MAS NMR can offer to chromatin structural biologists, discuss sample preparation strategies for structural analysis, summarize recent MAS NMR studies of chromatin structure and dynamics, and close by discussing how MAS NMR can be combined with state-of-the-art chemical biology tools to reconstitute and dissect complex chromatin environments.

Keywords: gene regulation, magic angle spinning, chemical biology, nucleosome dynamics, histone dynamics

\section{INTRODUCTION}

In the nuclei of eukaryotic cells, approximately $2 \mathrm{~m}$ of DNA must be packaged and organized for efficient gene regulation and DNA replication (Figure 1A). On a global level, this is achieved by separation into active gene regions called euchromatin and silent gene compartments known as heterochromatin. A fundamental molecular building block for such organization is the nucleosome, a complex of histone proteins ( 2 each of $\mathrm{H} 2 \mathrm{~A}, \mathrm{H} 2 \mathrm{~B}, \mathrm{H} 3$, and $\mathrm{H} 4$ ) assembled into an octamer and wrapped by $\sim 147$ base pairs of DNA. These nucleosome units repeat along the length of each chromosome to generate a "beads-on-a-string" polymer called chromatin (Woodcock et al., 1976) (Figure 1B). The interactions between histones and DNA are primarily electrostatic in nature, where the peripheral basic residues of the histone octamer intercalate into the phosphate backbone of wrapped DNA, while the dynamic histone termini (tails) transiently explore exposed DNA (Figure 1C). Since the majority of the genome is bound by histones, any modification of these interactions, however small, can alter genetic outcomes. Post-translational modifications (PTMs), for example, differentially mark histone tails to recruit specific histone readers (Kouzarides, 2007; 


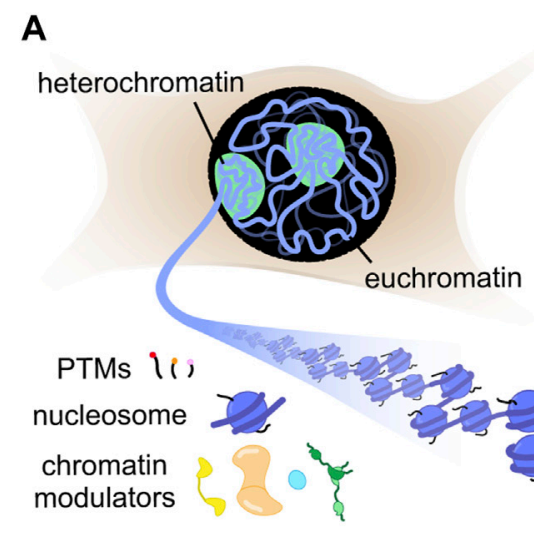

B

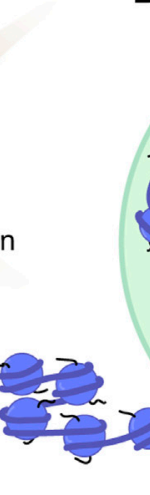

C

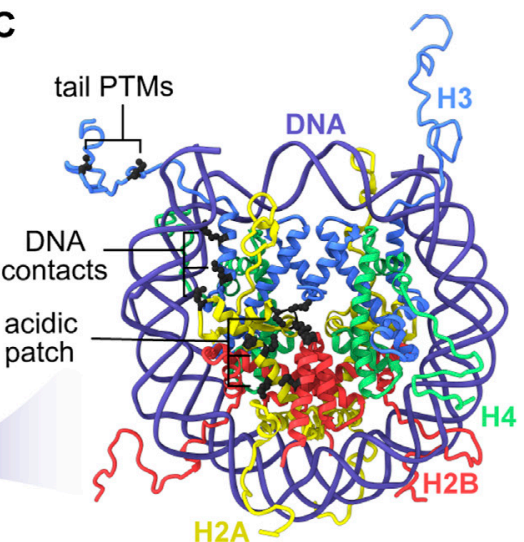

FIGURE 1 | Genome organization from the nucleus to the nucleosome. (A) The nucleus contains two distinct chromatin states, heterochromatin and euchromatin. Compact heterochromatin compartments may form by phase separation. (B) Chromatin fibers in different states contain distinct PTM signatures and interact with specific chromatin modulators. (C) The structure of the nucleosome with highlighted regions of interest for MAS NMR studies (PDB:1KX5) (Davey et al., 2002).

Prakash and Fournier, 2017) or to initiate DNA unwrapping (Bowman and Poirier, 2015). Macromolecular complexes that recognize such PTMs can further impact chromatin organization by cross-linking nucleosomes that are megabases apart in sequence (Rao et al., 2014; Strom et al., 2021), or by shifting the position of nucleosomes to expose new DNA sites for transcription initiation. Despite continuing progress towards determining the structure of chromatin in cells (Hsieh et al., 2015; Ricci et al., 2015; Nozaki et al., 2017; Ou et al., 2017; Risca et al., 2017; Cai et al., 2018; Xu et al., 2018; Ohno et al., 2019; Otterstrom et al., 2019; Krietenstein et al., 2020; Su et al., 2020), the impressive span of length scales involved, from small chemical modifications in the Angstrom range to whole chromosome rearrangements on the micrometer scale, creates a tremendous challenge for structural biologists and biophysicists.

Bottom-up approaches using purified components are well suited to systematically probe the interplay between nucleosomes and chromatin structure on the Ångstrom and nanometer scale (Allis and Muir, 2011). The isolation of mononucleosomes from their polymer context enables high-resolution structural biology where the rigid histone core can be studied by X-ray crystallography and cryo-EM, and the histone tails by solution NMR spectroscopy (McGinty et al., 2016; Zhou et al., 2019). Virtually any chromatin and DNA process has now been mapped on the nucleosome, including chromatin remodeling, transcription, histone/DNA modification, gene repression, and DNA repair (Jang and Song, 2019; Zhou et al., 2019; McGinty and Tan, 2021; Min and Liu, 2021). These studies have highlighted several cornerstones in nucleosome recognition and modification. The H2A-H2B acidic patch, a lone cluster of glutamate and aspartate residues on the nucleosome surface, serves as a landing pad to anchor chromatin modulators as well as nearby nucleosomes (Kalashnikova et al., 2013; Chen et al., 2017; McGinty and Tan, 2021) (Figure 1C). The histone tails are dynamic, enabling access to both modification and recognition. PTMs and sequence variation of histones dictate the dynamics of nucleosome sliding and unwrapping. The histone-induced bending of nucleosomal DNA elicits unique recognition motifs for protein interaction.

Building upon these studies, the interactions of many adjacent nucleosomes can be addressed. The chromatin context is important for biomolecular recognition; some chromatin modulator complexes are much larger than a nucleosome and can sense nearby nucleosomes (Yang et al., 2006; He et al., 2020), many architectural proteins are multivalent and can simultaneously interact with several nucleosomes (Machida et al., 2018; Poepsel et al., 2018), and neighboring nucleosomes can stack atop each other, thereby competing with chromatin modulators for binding sites (Bilokapic et al., 2018; Sanulli et al., 2019; Alvarado et al., 2021). The fiber context is also necessary for packaging, as nucleosomes are strung together and densities get closer to those observed in cells (10-100 mg/ml) (Imai et al., 2017; Hancock, 2018; Kim and Guck, 2020), chromatin can undergo phase separation into a highly viscous solid-like material (Strickfaden et al., 2020). Phase separation is a promising model for cellular compartmentalization (and more recently chromatin compaction) that depends on a large number of transient multivalent interactions (Gibson et al., 2019; Sanulli et al., 2019). While this setting better represents the native nucleosome competition and the physical forces of compaction, the heterogeneity and density of such nucleosome polymers become intractable to most structural techniques.

NMR spectroscopy rises to the forefront of techniques uniquely capable of probing atomic structural and dynamic information for complex samples. Solution NMR of proteins benefits from fast molecular rotation to average linebroadening anisotropic interactions. However, larger proteins or protein complexes may tumble too slowly for efficient averaging and may require the tools of solid-state NMR. Magic-angle spinning solid-state NMR spectroscopy (MAS NMR) achieves partial averaging by rapid (tens of kilohertz) rotation of the sample at $54.7^{\circ}$ (the magic angle) relative to the 


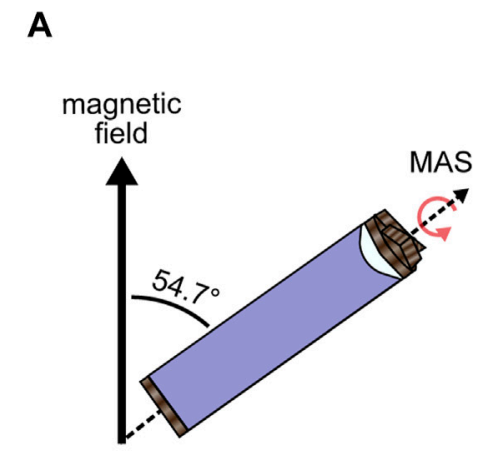

\section{C recombinant histones}
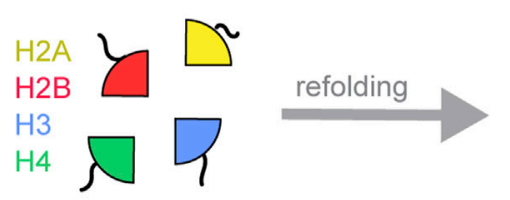

B
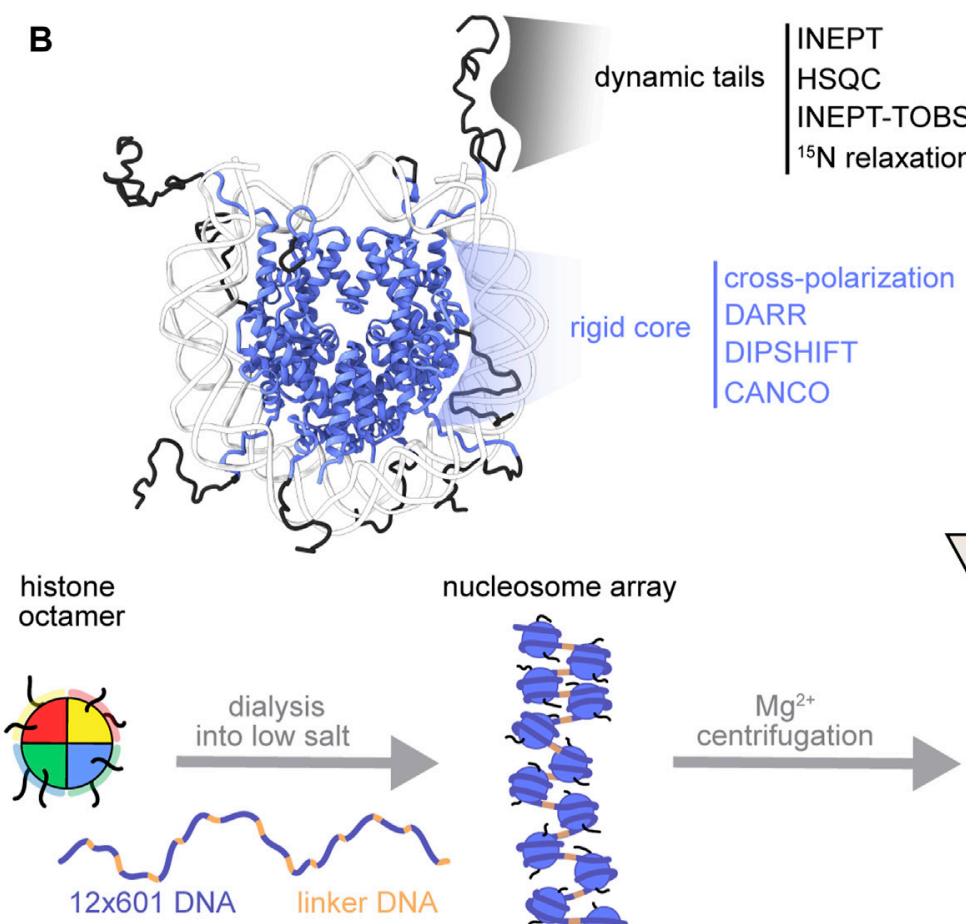

nucleosome array

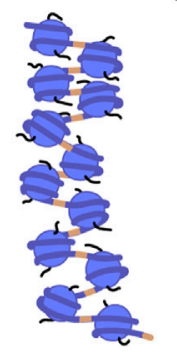

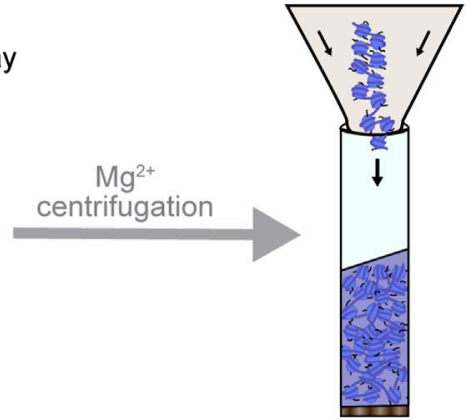

FIGURE 2 | MAS NMR toolbox for chromatin structural biology. (A) During MAS NMR, the sample rotor is spun at frequencies between 10 and $100 \mathrm{kHz}$ at the magic angle (54.7 ${ }^{\circ}$ relative to the external magnetic field). (B) MAS NMR can probe the dynamic range of the nucleosome with experiments designed to detect either the mobile histone tails or the rigid nucleosome core (PDB:1KX5) (Davey et al., 2002). (C) Chromatin reconstitution begins with the formation of histone octamers from recombinant histones, followed by DNA wrapping at low salt. $\mathrm{Mg}^{2+}$ can be used to purify arrays and to compact chromatin during rotor packing.

external magnetic field (Figure 2A). MAS thereby enables detection of large macromolecules in various material states (amorphous, crystalline, gel-like, liquid) (Quinn and Polenova, 2017; van der Wel, 2018). MAS NMR can detect both slow and fast biomolecular motions by using solution-state (INEPT) experiments that depend on through-bond scalar-couplings (Morris and Freeman, 1979; Andronesi et al., 2005) or by using solid-state cross-polarization (CP) experiments (Hartmann and Hahn, 1962; Pines et al., 1973) that rely on through-space dipolar interactions (Figure 2B). These two experiment types allow for qualitative dynamics-based spectral filtering (Matlahov and van der Wel, 2018), where INEPT selects for nuclei that undergo dynamic isotropic motion, and CP builds up signal for nuclei in rigid networks that maintain strong dipolar couplings. MAS NMR can also resolve distance parameters by recoupling spatially informative anisotropic interactions via pulse sequences matched to the sample spinning rate. These features of MAS NMR suit chromatin, a heterogenous polymer that forms an amorphous solid in vitro and in nucleo (Strickfaden et al., 2020), and that bears nucleosomes with both rigid histone cores and dynamic histone tails (Fierz and Poirier, 2019). Therefore, MAS NMR can detect the dynamic range of nucleosomes while embedded in the chromatin context. In this review, we will cover the practicalities of sample preparation for MAS NMR, highlight the current applications of MAS NMR to chromatin, and finally outline the next frontier of biologically compelling chromatin design and structural analysis. Readers interested in chromatin applications of other structural techniques such as solution NMR spectroscopy, X-ray crystallography and cryo-EM are referred to several recent comprehensive reviews on these topics (van Emmerik and van Ingen, 2019; Zhou et al., 2019; McGinty and Tan, 2021).

\section{CHROMATIN SAMPLE PREPARATION FOR MAS NMR}

The chromatin fiber, while richly decorated in cells with PTMs, histone variants and chromatin modulators, can be minimally reconstructed using purified DNA and recombinant histones (Figure 2C). Mononucleosomes and nucleosome arrays were first reconstituted by depositing histone octamers onto alphasatellite DNA and tandem-repeat $5 \mathrm{~S}$ rDNA, respectively (Simpson et al., 1985; Luger et al., 1997; Fierz and Muir, 2012). The discovery of the high-affinity 601 positioning sequence soon revolutionized chromatin construction by enabling the efficient assembly of highly homogenous chromatin preparations (Lowary and Widom, 1998). The 601 DNA is now favored in most in vitro biochemical and structural chromatin studies. Nucleosome arrays have been standardized to include twelve 601 sequence repeats, partitioned by selected lengths of linker DNA (Huynh et al., 2005). The 12-mer 
DNA, along with a short helper DNA strand that assists later steps, are cloned for bacterial production on a large scale (tens of milligrams). Histone octamers, on the other hand, are formed by refolding a stoichiometric mixture of the four histone proteins, typically produced recombinantly in E. coli and thus devoid of PTMs. For NMR studies, the histone of interest is expressed in isotopically enriched media which leads to a selectively labeled histone type within the otherwise NMR-silent nucleosome complex. Finally, the repetitive DNA and helper DNA strands are excised from their parent plasmids and loaded with octamers by the salt dialysis assembly method to produce well-defined and spaced nucleosome arrays (Dorigo et al., 2003; Dyer et al., 2003; Fyodorov and Kadonaga, 2003) (Figure 2C). The helper DNA, which has a weaker affinity for histones, is essential for soaking up the excess histone octamers required to saturate the twelve nucleosome sites in the array. Nucleosome arrays can then be purified from helper DNA by a facile $\mathrm{Mg}^{2+}$ precipitation step, in contrast to mononucleosomes which require sucrose gradient or preparative gel purifications to remove leftover DNA. Homotypic and heterotypic post-translationally modified nucleosome arrays can be produced using native chemical ligation, expressed protein ligation, unnatural amino acid incorporation and other chemical approaches (Müller and Muir, 2015; Muller et al., 2016). While these methods typically yield small amounts of modified nucleosome arrays, some can be adapted to the high sample demands of NMR spectroscopy. We will briefly discuss those in the last section of this review.

The development of efficient and reliable protocols for chromatin assembly has led to fundamental insights into chromatin structure. For example, it is now well known that the $\mathrm{H} 4$ tail and the $\mathrm{H} 2 \mathrm{~A} / \mathrm{H} 2 \mathrm{~B}$ acidic patch are critical for internucleosome stacking (Dorigo et al., 2003; Zhou et al., 2007; Lu et al., 2008) while lysine acetylation on the H4 tail can open up the chromatin fiber and expose DNA (Shogren-Knaak, 2006; Mishra et al., 2016). Chromatin reconstitution was also vital for uncovering the structural continuum of extended $10-\mathrm{nm}$ fibers, folded $30-\mathrm{nm}$ fibers, interdigitated fibers, and irregular globules that depend on $\mathrm{Mg}^{2+}$ concentration, DNA linker length, linker histone H1, and array concentration (Baldi et al., 2018; Maeshima et al., 2019; Adhireksan et al., 2020; Brouwer et al., 2021). Despite the detection of structured high-order fibers in vitro, recent studies emphasize that interphase chromatin appears to compact irregularly at densities up to $100 \mathrm{mg} / \mathrm{ml}$ (Poirier et al., 2009; Hihara et al., 2012; Imai et al., 2017; Cai et al., 2018; Hancock, 2018; Kilic et al., 2018; Audugé et al., 2019). Careful preparation and explicit characterization of chromatin states stands as a crucial step to identify the specialized structures that relate to functions such as gene repression, mitosis, and transcription (Luger et al., 2012).

MAS NMR is well suited to tackle macroscopically heterogenous samples that emulate the irregularity of nuclear chromatin. Non-crystalline samples are routinely packaged for analysis by ultracentrifugation (Bertini et al., 2013; Mandal et al., 2017), where high gravity values generate maximally concentrated sediments of macromolecules while retaining sample hydration and stability for years (Fragai et al., 2013; Wiegand et al., 2020). Sedimentation can be performed in several ways; the sample can be centrifuged inside a tube and then transferred to a rotor, centrifuged directly into a rotor, or sedimented inside the rotor during MAS (Bertini et al., 2013; Mandal et al., 2017). The rate of sedimentation depends on the degree of chromatin compaction (Dorigo et al., 2003) and the process can be sped up by the addition of $\mathrm{Mg}^{2+}$ ions. Divalent cations shield the repulsive electrostatic interactions between nucleosomes to compact and eventually aggregate nucleosome arrays. Despite this benefit for MAS NMR studies, $\mathrm{Mg}^{2+}$ presents a conundrum for sample preparation due to its profound effect on chromatin structure (Berezhnoy et al., 2016) and inconclusive results regarding its physiological concentrations in the nucleus (Maeshima et al., 2018). As a result, it is important to study chromatin in various buffer conditions and rigorously compare the outcomes. Arrays and mononucleosomes have been prepared for MAS NMR with and without $\mathrm{Mg}^{2+}$-induced precipitation (Gao et al., 2013; le Paige et al., 2021). Mononucleosome sediments with low levels of $\mathrm{Mg}^{2+}$ lacked the long-range order expected for stacked fibers formed by high $\mathrm{Mg}^{2+}$ concentrations (le Paige et al., 2021). Such irregular packing may illuminate the transient nucleosome-nucleosome interactions that dominate when nucleosomes are not restricted into ordered arrays (Bilokapic et al., 2018; Sanulli et al., 2019; Alvarado et al., 2021). Thus, samples prepared by sedimentation and low $\mathrm{Mg}^{2+}$ concentrations may prove crucial for resolving the transient interactions that lead to chromatin compaction and regulation (Gibson et al., 2019; Khanna et al., 2019; Sanulli et al., 2019; Kantidze and Razin, 2020).

\section{MAS NMR OF HISTONE TAILS}

The flexible $\mathrm{N}$ - and C-terminal histone tails extend from the nucleosome, each with a distinct interaction profile and PTM landscape. The histone tails have been the subject of numerous biochemical and biophysical studies that have revealed their important role in chromatin structure, function, and regulation (Peng et al., 2021). While these dynamic segments are rarely visible on their own in X-ray and cryo-EM structural models, they can be studied by both solution and MAS NMR spectroscopy. The first MAS NMR study by Gao et al. used INEPT-based experiments to map the amino acid specific dynamics of the H3 and H4 tails within arrays at different $\mathrm{Mg}^{2+}$ concentrations (Gao et al., 2013). The histone tails remained dynamic regardless of the $\mathrm{Mg}^{2+}$ concentration used (0-5 mM), arguing for a much more flexible landscape than suggested previously by X-ray crystallography and hydrogendeuterium exchange experiments (Luger et al., 1997; Kato et al., 2009). $2 \mathrm{D}{ }^{1} \mathrm{H}_{-}{ }^{13} \mathrm{C}$ and ${ }^{1} \mathrm{H}_{-}{ }^{15} \mathrm{~N}$ correlations revealed identifiable amino acids signatures that made it possible to compare the information content of INEPT-based experiments under solution and MAS NMR conditions. For example, Val 35, a unique amino acid in the $\mathrm{H} 3$ tail, was visible in both solution and MAS NMR spectra, while residues up to Val 21 were detected in the MAS NMR experiments of $\mathrm{H} 4$, in contrast to solution NMR experiments where only residues up to Ala 15 were present (Zhou et al., 2012; Morrison et al., 2021; Rabdano et al., 
2021). Subsequent MAS NMR studies of mononucleosomes by Shi et al. also confirmed these observations (Shi et al., 2018). This discrepancy is most likely due to the type of experiments used (i.e., sidechain vs. backbone correlations), with ${ }^{13} \mathrm{C}$ MAS NMR experiments holding a slight advantage regarding the detection of slower moving tail sidechains such as those that are close to the DNA interface (Shi et al., 2018; Shi et al., 2020b). While the detected tail boundary is consistent between arrays and mononucleosomes in MAS NMR experiments, a closer look into the ${ }^{15} \mathrm{~N}$ spin relaxation rates of $\mathrm{H} 3$ tails reveals mobility differences (Zandian et al., 2021). Here, $\mathrm{T}_{1}$ and $\mathrm{T}_{1 \rho}$ relaxation measurements were used to quantify residue-specific rotational correlation times. The $\mathrm{H} 3$ tail was most dynamic in $147 \mathrm{bp}$ mononucleosomes, the mobility was diminished by linker DNA extensions and was further reduced in nucleosome arrays. These results are consistent with solution NMR studies that show $\mathrm{H} 3$ tail dynamics to be regulated by transient DNA contacts (Stutzer et al., 2016).

Histone tail interactions with DNA can tuned by the chemical properties of specific PTMs. H4 lysine 20 trimethylation (H4 $\mathrm{K} 20 \mathrm{me}$ ), for example, is a hydrophobic modification thought to increase the compaction of nucleosome arrays by altering the adjacent residue side-chain interactions with DNA ( $\mathrm{Lu}$ et al., 2008). Shoaib et al. used MAS NMR to show that H4 K20 monoand tri-methylation differentially dictate tail conformation and lead to either open or closed chromatin states, respectively (Shoaib et al., 2021). These conclusions were based on genomic accessibility studies, $\mathrm{Mg}^{2+}$ precipitation experiments and $2 \mathrm{D}{ }^{1} \mathrm{H}-{ }^{13} \mathrm{C}$ INEPT correlations that focused on Val 21, a residue that is, adjacent to the modification site. Surprisingly, the Val $21 \mathrm{Ha}$-Ca correlation was split into two peaks for the nonand tri-methylated samples but only one peak was visible for the monomethylated $\mathrm{H} 4$ tail. While it is not yet clear how these changes in $\mathrm{H} 4$ tail dynamics and structure bring about open or closed chromatin states, this study exemplifies the power of MAS NMR to monitor tail dynamics in the context of nucleosome arrays where the inter-nucleosome contacts are essential to the structural hypothesis.

MAS NMR has also revealed that histone tails can sense their local environment and drive chromatin compaction while remaining dynamic and potentially accessible to regulatory proteins. A recent study by le Paige et al. confirmed that the dynamic tails sustain accessibility within dense sedimented samples (le Paige et al., 2021). In this case, the interactions of the histone reader domain PHD2 with histone $\mathrm{H} 3$ were compared by INEPT-based experiments in nucleosome sediments and under dilute conditions. For MAS NMR, PHD2 was cosedimented with nucleosomes during ultracentrifugation, while the dilute samples could be analyzed by solution NMR. The fast MAS rate of $50 \mathrm{kHz}$ afforded ${ }^{1} \mathrm{H}$-detection and generated highly resolved spectra of the histone tail backbone. Crucially, the spectral quality provided residue-specific assignments to directly compare the isotropic chemical shifts with solution NMR experiments. PHD2 binding produced comparable ${ }^{1} \mathrm{H}-$ ${ }^{15} \mathrm{~N}$ resonance broadening of residues $3-10$ in both conditions. While the weak affinity of PHD2 complicated quantitative comparison of binding interactions, this study confirmed the permeability of dense chromatin environments to histone readers. This strategy will undoubtedly prove useful in future experiments aimed to dissect the interactions between histone readers and their nucleosome binding sites.

\section{MAS NMR OF THE NUCLEOSOME CORE}

While the dynamic histone tails are a major target for modification and binding, sequence variations, PTMs and disease-related mutations also embroider the nucleosome core and can disturb fundamental processes like nucleosome sliding, histone exchange, and DNA wrapping (Bowman and Poirier, 2015; Fenley et al., 2018; Bryant et al., 2020; Bagert et al., 2021). In addition, many chromatin readers interact with the nucleosome core which provides additional interaction surfaces through the $\mathrm{H} 2 \mathrm{~A} / \mathrm{H} 2 \mathrm{~B}$ acidic patch and the histone/DNA interface. Solution NMR, and in particular methyl-TROSY spectroscopy, has illuminated nucleosome core motions resulting from histone mutations (Kitevski-LeBlanc et al., 2018), DNA methylation (Abramov et al., 2020), and interacting proteins (Kato et al., 2011; Sanulli et al., 2019). However, only a few amino acid types are typically detectable due to the necessary methyl-labeling scheme. A major advantage of MAS NMR is the ability to characterize the entire nucleosome core in the same samples and conditions as those used to analyze the dynamic histone tails. The Nordenskiöld lab has pioneered MAS NMR of the nucleosome core by extensively assigning the highly resolved histone $\mathrm{H} 3$ and $\mathrm{H} 4$ spectra obtained with $\mathrm{CP}$-based ${ }^{15} \mathrm{~N}-{ }^{13} \mathrm{C}-{ }^{13} \mathrm{C}$ three-dimensional experiments (Shi et al., 2018; Shi et al., 2020a). In the first of several studies, histone H4-labeled mononucleosomes and 12-mer arrays were $\mathrm{Mg}^{2+}$-precipitated and subjected to CANCO and quantitative DIPSHIFT experiments which capture motion on a wide ns-ms timescale (Munowitz et al., 1982; Shi et al., 2018). Motions at the ns-scale involve side-chain fluctuations and $\mu \mathrm{s}-\mathrm{ms}$ motions correspond to larger domain movements (Lewandowski, 2013). The array and mononucleosome samples were consistent in overall structure and dynamics. Small signal intensity differences were observed for residues adjacent to the $\mathrm{N}$-terminal $\mathrm{H} 4$ tail, suggesting that the base of the tail is more rigid in the chromatin fiber. The mononucleosome samples in this study were precipitated with $20 \mathrm{mM} \mathrm{Mg}^{2+}$ which generates columnar stacked assemblies that may dictate histone dynamics and influence interpretation (Berezhnoy et al., 2016). Nonetheless, the precedent of quantitative dynamic parameters for each histone residue created a platform for probing other histones and DNA sequences.

Histone $\mathrm{H} 3$ spectra soon followed, illustrating that both $\mathrm{H} 3$ and $\mathrm{H} 4$ experience some ns- $\mu$ s motions and have regional clusters of moderately altered $\mu$ s-ms motions and highly dynamic termini (Shi et al., 2018; Shi et al., 2020b). Together, these results suggest histone $\mathrm{H} 3$ and $\mathrm{H} 4$ form stable folds but can undergo local intermediate motions. When these motions are mapped on the nucleosome structure, small neighboring clusters of dynamic sites connect from the nucleosome core to the DNA-bound periphery. Correlative motions of residues that contact DNA may be 
important for regulating biological processes like DNA wrapping, sliding, and nucleosome assembly (Bowman and Poirier, 2015; Sinha et al., 2017; Sanulli et al., 2019; Bagert et al., 2021). The connection between histone and DNA dynamics was supported by comparing nucleosomes formed with the 601 sequence to those prepared with a tandem-repeat (TTAGGG) telomere sequence. The TTAGGG nucleosomes displayed a greater range of motions in the cluster network compared to the 601 nucleosomes consistent with previous experiments which showed that telomeric nucleosomes are less stable and wrap DNA less tightly (Shi et al., 2020b; Soman et al., 2020). Reduced nucleosome stability may translate into more flexible chromatin fibers that in turn enhance the potential for phase separation at telomeres (Sanulli et al., 2019; Farr et al., 2021). Here, MAS NMR greatly contributed to establishing a connection between histone core dynamics and the compaction of chromatin fibers. Further broadening the scope of DNA to include other genetic sequences and DNA modifications will allow MAS NMR to bridge the vast expanse of genomic data with nucleosomespecific dynamics.

MAS NMR has also been used to detect interactions between the nucleosome core and regulatory proteins. The Baldus and van Ingen labs have demonstrated the sensitivity of MAS NMR to chemical environment changes when the $\mathrm{H} 2 \mathrm{~A} / \mathrm{H} 2 \mathrm{~B}$ acidic patch is bound by a peptide segment of the viral LANA protein (Xiang et al., 2018). In this study, LANA and mononucleosomes were cosedimented with $2 \mathrm{mM} \mathrm{Mg}^{2+} .{ }^{1} \mathrm{H}$-detected $\mathrm{CP}$ experiments were used to assign $93 \%$ of the $\mathrm{H} 2 \mathrm{~A}$ core backbone, locate the LANA binding site, and independently model the binding conformation in agreement to the crystal structure. ${ }^{1} \mathrm{H}$-detection was crucial to observe significant chemical shift perturbations (CSPs) that were diminished in the ${ }^{13} \mathrm{C}$ and ${ }^{15} \mathrm{~N}$ dimensions. Importantly, the absence of peak-splitting suggests that the LANA peptide bound both sides of the nucleosome simultaneously. Such an observation is important because the LANA peptide affects chromatin compaction by shielding the acidic patch (Chodaparambil et al., 2007). Detection of acidic patch interactions by ${ }^{1} \mathrm{H}$-detected MAS NMR holds promise for studying the myriad of chromatin modulators that use basic disordered segments to bind the nucleosome (Mashtalir et al., 2020; Teles et al., 2020).

\section{MAS NMR OF CHROMATIN MODULATORS}

Almost all MAS NMR studies of chromatin so far have focused on the nucleosome perspective, while the structure, dynamics, and interactions of chromatin modulators have largely remained unexplored. Here, MAS NMR can offer unique advantages as often chromatin modulators are too large to study by solution NMR or they form dynamic, viscous and heterogenous phase separated states that cannot be dissected by single particle techniques such as cryo-EM. Most importantly, however, such studies can be performed in the presence of mononucleosomes or nucleosome arrays where isotopic labeling of each protein one at a time can provide an opportunity to analyze a single component at high resolution in the complex chromatin-modulator assembly. A study from our lab used MAS NMR to illuminate the liquid-liquid phase separation of phosphorylated heterochromatin protein $1 \alpha$ (pHP1a) in the presence and absence of nucleosome arrays (Ackermann and Debelouchina, 2019). HP1a is a key chromatin modulator responsible for the formation of heterochromatin domains in the nucleus where silenced genes are sequestered (Cheutin, 2003). N-terminal serine phosphorylation was previously found to enhance the phase separation behavior of HP1a and to promote the transition from dynamic liquid to an arrested gel state (Larson et al., 2017). To measure the phenomenon in a more physiological chromatin environment, phase separated and isotopically labeled pHP1a was packaged into MAS rotors with and without H3 lysine 9 trimethylated nucleosome arrays, the native binding partner for pHPla. Both INEPT and CP experiments were employed to measure the sample dynamics during gelation. The addition of chromatin appeared to disrupt the pHPlapHP1 $\alpha$ gel network as detected by the lower overall CP signal for pHP1 $\alpha$. In addition, 2D INEPT-TOBSY and CP-based DARR ${ }^{13} \mathrm{C}-{ }^{13} \mathrm{C}$ correlations revealed changes in the dynamics of specific serine residues as pHP1a transitioned from the liquid to the gel state. In this case, MAS NMR provided an opportunity to observe in real time molecular interactions that underlie the formation of phase separated chromatin environments. As many chromatin modulators are now known to undergo phase separation (Weber, 2019), these unique capabilities of MAS NMR can no doubt be exploited further to provide a much needed molecular view of this complex biological process.

\section{CHEMICAL BIOLOGY TOOLS FOR MAS NMR OF MODIFIED CHROMATIN SAMPLES}

So far, MAS NMR studies of chromatin have largely used samples prepared with recombinant histones that are devoid of PTMs. Considering the importance of histone modifications in defining chromatin structure, dynamics and function, it is necessary to consider efficient and specific modification strategies that are compatible with isotopic labeling. In some serendipitous cases, enzymatic modification during expression in E. coli or after purification may produce homogeneously modified proteins. For example, we have used co-expression with the kinase CK2 to prepare isotopically labeled and well-defined phosphorylated HP1a samples with high yields (Ackermann and Debelouchina, 2019). More often, however, enzymatic approaches result in incomplete or off target modifications. Therefore, chemical approaches that introduce PTMs in a well-defined and controlled manner are highly desirable (Debelouchina and Muir, 2017).

Chromatin templates have long served as an expansive and challenging canvas for the development of chemical biology methods for protein modification (Allis and Muir, 2011). The histone proteins are relatively small (ranging in size from 100 to 150 amino acids) and practically devoid of cysteine residues (the lone Cys110 on H3.2 can easily be replaced with an alanine or serine residue without loss of structure or function). This makes the application of cysteine-based modification approaches 


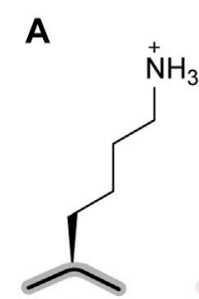

lysine

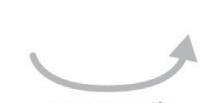

enzymatic

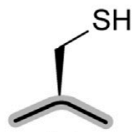

cysteine

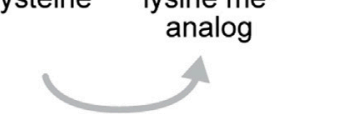

cysteine alkylation

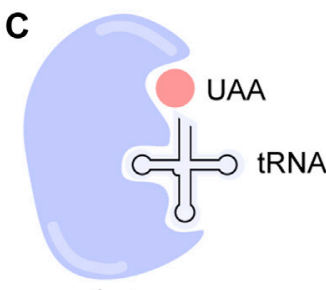

synthetase
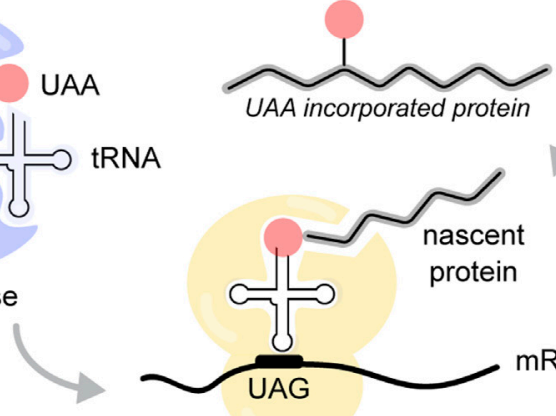

UAA incorporated protein

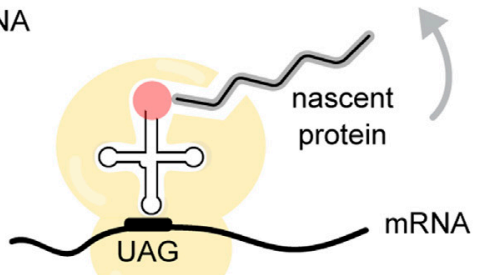

ribosome

B<smiles>[R7]C(=O)CCCC(C)C(C)C</smiles>

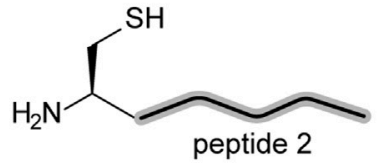

peptide 2

D

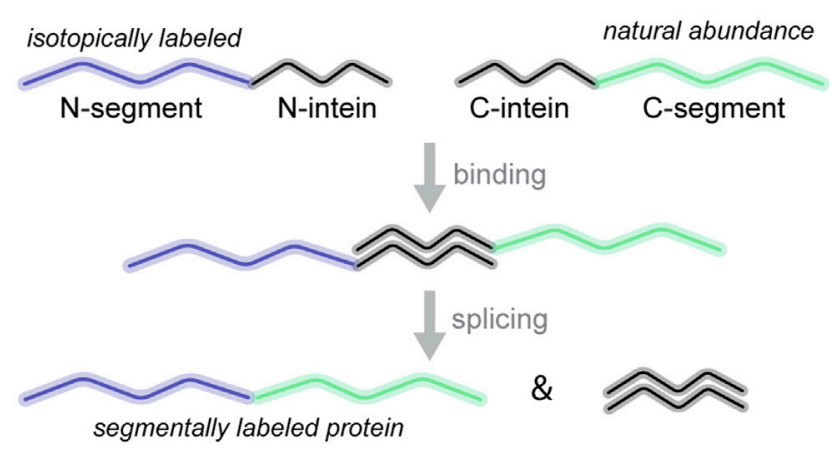

FIGURE 3 | Chemical biology toolbox for chromatin studies. (A) Lysine trimethylation (me ${ }^{3}$ ) can be installed enzymatically or by cysteine alkylation to yield a methylated lysine analog. (B) In native chemical ligation, a synthetic peptide containing a C-terminal thioester (1) is linked to a second polypeptide bearing an N-terminal cysteine (2). (C) In unnatural amino acid incorporation, the UAA is loaded onto the corresponding tRNA by an engineered tRNA synthetase. The tRNA recognizes the amber stop codon UAG, allowing the ribosome to install the UAA at the desired position in the protein sequence. (D) Segmental isotopic labeling is mediated by intein splicing of an isotopically labeled protein segment with a segment at natural abundance, producing the full-length protein.

relatively straightforward (Chalker et al., 2009; Boutureira and Bernardes, 2015). Cysteine modification, for example, has been widely used to introduce spectroscopic probes, including fluorescent labels and paramagnetic relaxation enhancement (PRE) tags. More importantly, however, cysteine alkylation provides a convenient and efficient strategy to prepare lysine methylation mimics (Simon et al., 2007). In this case, the targeted lysine residue is replaced with a cysteine, and the cysteine is modified with mono-, di-, or trimethyl containing alkylating reagents (Figure 3A). The reaction is usually performed with the purified protein under denaturing conditions and is compatible with isotopic labeling provided that the protein can be refolded. While the resulting mimic contains a sulfur instead of a carbon atom at the $\gamma$ position of the side chain, in vitro biochemical studies have shown that this mimic can faithfully reproduce the functional consequences of lysine methylation (Simon et al., 2007). We have successfully used this strategy to prepare large amounts of nucleosome array samples that contained $\mathrm{H} 3$ K9me3 (Ackermann and Debelouchina, 2019), the relevant modification for HP1a binding and heterochromatin formation. This strategy was also used to explore the effects of K20 methylation on the dynamics of the H4 tail (Shoaib et al., 2021).

Multiple PTMs can be introduced with a technique called native chemical ligation (NCL) (Dawson and Kent, 2000). In this case, the $\mathrm{N}$-terminal segment of the protein (typically the first 10 to 50 residues) is made by solid-phase peptide synthesis and posttranslationally modified amino acids can be introduced at specific positions in the sequence as desired (Figure 3B). The peptide ends with a C-terminal thioester necessary for the subsequent ligation step. At the same time, the remaining C-terminal segment of the protein can be prepared recombinantly in E.coli with or without isotopic labeling (Muir et al., 1998). This segment requires an $\mathrm{N}$-terminal cysteine for ligation. Upon mixing, the synthetic peptide and the recombinant piece undergo a set of thio-esterification steps that result in a native peptide bond at the ligation junction. If necessary, the cysteine residue at the junction can be converted to an alanine by desulfurization (Yan and Dawson, 2001). It is also possible to adapt this technique to perform three-piece ligations and to introduce modifications in the middle or the C-terminal segment of the histone protein (Hackeng et al., 1999). The unprecedented chemical control and versatility of NCL has been used to construct large libraries (with more than 100 members) of uniquely modified nucleosomes and to elucidate the mechanisms of chromatin remodeling and multivalent PTM readout (Nguyen et al., 2014; Dann et al., 2017). While NCL has not yet been applied for MAS NMR of chromatin, it has been impactful in numerous solution and MAS NMR studies of other proteins (Kwon et al., 2015; Zoukimian et al., 2019). 
Bypassing the need for cysteines and synthesis, single PTMs can be introduced into proteins using unnatural amino acid (UAA) incorporation by genetic means (amber suppression) (Lang and Chin, 2014) (Figure 3C). Typically, the amber stop codon (TAG/UAG) is used to signal the position where the unnatural amino acid will be placed. To interpret this message correctly, the ribosome requires an engineered tRNA that can recognize this codon and is loaded with the UAA. The tRNA and the gene for an appropriately engineered matching tRNA synthetase that loads the UAA onto the tRNA are typically encoded onto a separate plasmid. E. coli cultures are then transformed with the tRNA/tRNA synthetase plasmid and a plasmid that contains the gene for the protein of interest with the TAG mutation. The unnatural amino acid is added to the media, and expression and purification of the modified protein can be performed as usual. While amber suppression systems have been engineered for the introduction of more than 100 UAAs (Liu and Schultz, 2010), the UAAs of particular interest to the chromatin structural biologist are acetylated lysine, phosphorylated serine and UAA precursors that can be converted into methylated amino acids (Neumann et al., 2008; Pirman et al., 2015; Wang and Liu, 2017). The major drawback of amber suppression for MAS NMR studies of chromatin is that it results in much lower yields of the desired protein, a situation that can be severely exacerbated under isotopic labeling conditions. Nevertheless, we have successfully used this technique to introduce UAAs in different isotopically labeled proteins, including some that are relevant for chromatin studies (Lim et al., 2020).

Finally, it is important to mention intein-mediated segmental labeling (Muir et al., 1998; Shah and Muir, 2014), a useful tool for proteins with congested NMR spectra (Züger and Iwai, 2005; Schubeis et al., 2015; Frederick et al., 2017; Gupta and Tycko, 2018; Wiegand et al., 2018; Ciragan et al., 2020) (Figure 3D). Split inteins are a class of proteins found in unicellular organisms that can "stitch" together other protein segments with a native peptide bond. To prepare segmentally labeled samples for NMR spectroscopy, the desired protein is split into two segments. The N-terminal segment is attached to an N-terminal split intein while the $\mathrm{C}$-terminal segment is attached to the matching C-terminal intein piece. The $\mathrm{N}$ - and $\mathrm{C}$-segments can be prepared independently in different cultures, for example, one using ${ }^{13} \mathrm{C},{ }^{15} \mathrm{~N}$ labeling and the other at natural abundance. Once the segments are purified, mixing of the segments results in an interaction between the intein pieces which adopt a functional intein fold. The intein mediates the formation of a native peptide bond between the two protein segments while excising itself in the process. This process requires a cysteine residue at the ligation junction. The result is a full-length protein with only a segment of the sequence visible by NMR, thereby simplifying the acquired spectra. This can aid assignment protocols (Iwai and Züger, 2007) and provide the opportunity to probe specific inter- or intramolecular interactions (Frederick et al., 2017). There is now a large variety of efficient split intein pairs that can be used for this purpose (Pinto et al., 2020), including some that work well under denaturing conditions (Stevens et al., 2016). We envision that this technique will be extremely valuable in the resonance assignment and MAS NMR analysis of chromatin interacting proteins.

\section{DISCUSSION}

While still few in number, the recent applications of MAS NMR have demonstrated its versatile capabilities in the structural analysis of chromatin samples. Uniquely capable of characterizing both the rigid and dynamic components of mononucleosome and array preparations, precipitated, sedimented, and concentrated samples, chromatin MAS NMR has illuminated fundamental aspects of nucleosome dynamics, histone tail recognition, acidic patch docking, and heterochromatin phase separation. Most chromatin experiments so far have relied on dipolar and scalar based experiments performed at moderate spinning frequencies $(10-20 \mathrm{kHz})$ and the detection and analysis of ${ }^{13} \mathrm{C}$ and ${ }^{15} \mathrm{~N}$ signals. We expect that ${ }^{1} \mathrm{H}$-detection and fast MAS (at $100 \mathrm{kHz}$ and beyond) will continue to improve signal sensitivity and facilitate the resolution of chemical shift perturbations and chromatin interactions (Andreas et al., 2016; Struppe et al., 2017). Since chromatin assemblies contain multiple proteins and DNA, the preparation of large amounts of isotopically labeled samples can be time consuming and challenging, especially if chromatin interacting proteins or PTMs are included. We therefore expect that such samples will benefit tremendously from sensitivity-enhancement developments such as dynamic nuclear polarization and cryoMAS probes (Lilly Thankamony et al., 2017; Hassan et al., 2020). Chemical biology tools such as cysteine alkylation, native chemical ligation and amber suppression enable the preparation of specifically decorated chromatin, while inteins allow the simplification of crowded histone or chromatin reader spectra. We envision that the combination of chemical biology tools and MAS NMR will provide the unprecedented opportunity to construct and dissect complex chromatin environments where dynamic multifaceted interactions can be interrogated one at a time.

\section{AUTHOR CONTRIBUTIONS}

BA prepared the figure images. BA and GD wrote the article.

\section{FUNDING}

This work was supported by NIH R35 GM138382 grant to GD and T32 GM008326 fellowship to BA. 


\section{REFERENCES}

Abramov, G., Velyvis, A., Rennella, E., Wong, L. E., and Kay, L. E. (2020). A Methyl-TROSY Approach for NMR Studies of High-Molecular-Weight DNA with Application to the Nucleosome Core Particle. Proc. Natl. Acad. Sci. USA 117 (23), 12836-12846. doi:10.1073/pnas.2004317117

Ackermann, B. E., and Debelouchina, G. T. (2019). Heterochromatin Protein HP1 $\alpha$ Gelation Dynamics Revealed by Solid-State NMR Spectroscopy. Angew. Chem. Int. Ed. 58 (19), 6300-6305. doi:10.1002/anie.201901141

Adhireksan, Z., Sharma, D., Lee, P. L., and Davey, C. A. (2020). Near-atomic Resolution Structures of Interdigitated Nucleosome Fibres. Nat. Commun. 11 (1), 4747. doi:10.1038/s41467-020-18533-2

Allis, C. D., and Muir, T. W. (2011). Spreading Chromatin into Chemical Biology. ChemBioChem 12 (2), 264-279. doi:10.1002/cbic.201000761

Alvarado, W., Moller, J., Ferguson, A. L., and de Pablo, J. J. (2021). Tetranucleosome Interactions Drive Chromatin Folding. ACS Cent. Sci. 7, 1019-1027. doi:10.1021/acscentsci.1c00085

Andreas, L. B., Jaudzems, K., Stanek, J., Lalli, D., Bertarello, A., Le Marchand, T., et al. (2016). Structure of Fully Protonated Proteins by Proton-Detected MagicAngle Spinning NMR. Proc. Natl. Acad. Sci. USA 113 (33), 9187-9192. doi:10.1073/pnas. 1602248113

Andronesi, O. C., Becker, S., Seidel, K., Heise, H., Young, H. S., and Baldus, M. (2005). Determination of Membrane Protein Structure and Dynamics by Magic-Angle-Spinning Solid-State NMR Spectroscopy†. J. Am. Chem. Soc. 127 (37), 12965-12974. doi:10.1021/ja0530164

Audugé, N., Padilla-Parra, S., Tramier, M., Borghi, N., and Coppey-Moisan, M. (2019). Chromatin Condensation Fluctuations rather Than Steady-State Predict Chromatin Accessibility. Nucleic Acids Res. 47 (12), 6184-6194. doi:10.1093/nar/gkz373

Bagert, J. D., Mitchener, M. M., Patriotis, A. L., Dul, B. E., Wojcik, F., Nacev, B. A., et al. (2021). Oncohistone Mutations Enhance Chromatin Remodeling and Alter Cell Fates. Nat. Chem. Biol. 17, 403-411. doi:10.1038/s41589-02100738-1

Baldi, S., Krebs, S., Blum, H., and Becker, P. B. (2018). Genome-wide Measurement of Local Nucleosome Array Regularity and Spacing by Nanopore Sequencing. Nat. Struct. Mol. Biol. 25, 894-901. doi:10.1038/s41594-018-0110-0

Berezhnoy, N. V., Liu, Y., Allahverdi, A., Yang, R., Su, C.-J., Liu, C.-F., et al. (2016). The Influence of Ionic Environment and Histone Tails on Columnar Order of Nucleosome Core Particles. Biophys. J. 110 (8), 1720-1731. doi:10.1016/ j.bpj.2016.03.016

Bertini, I., Luchinat, C., Parigi, G., and Ravera, E. (2013). SedNMR: On the Edge between Solution and Solid-State NMR. Acc. Chem. Res. 46 (9), 2059-2069. doi:10.1021/ar300342f

Bilokapic, S., Strauss, M., and Halic, M. (2018). Cryo-EM of Nucleosome Core Particle Interactions in Trans. Sci. Rep. 8 (1), 7046. doi:10.1038/s41598-01825429-1

Boutureira, O., and Bernardes, G. J. L. (2015). Advances in Chemical Protein Modification. Chem. Rev. 115 (5), 2174-2195. doi:10.1021/cr500399p

Bowman, G. D., and Poirier, M. G. (2015). Post-Translational Modifications of Histones that Influence Nucleosome Dynamics. Chem. Rev. 115 (6), 2274-2295. doi:10.1021/cr500350x

Brouwer, T., Pham, C., Kaczmarczyk, A., de Voogd, W.-J., Botto, M., Vizjak, P., et al. (2021). A Critical Role for Linker DNA in Higher-Order Folding of Chromatin Fibers. Nucleic Acids Res. 49 (5), 2537-2551. doi:10.1093/nar/ gkab058

Bryant, L., Li, D., Cox, S. G., Marchione, D., Joiner, E. F., Wilson, K., et al. (2020). Histone H3.3 beyond Cancer: Germline Mutations in Histone 3 Family 3A and 3B Cause a Previously Unidentified Neurodegenerative Disorder in 46 Patients. Sci. Adv. 6 (49), eabc9207. doi:10.1126/sciadv.abc9207

Cai, S., Böck, D., Pilhofer, M., and Gan, L. (2018). The In Situ Structures of Mono-, Di-, and Tri-nucleosomes in Human Heterochromatin. Mol. Biol. Cel. 29, 2450-2457. doi:10.1091/mbc.E18-05-0331

Chalker, J. M., Bernardes, G. J. L., Lin, Y. A., and Davis, B. G. (2009). Chemical Modification of Proteins at Cysteine: Opportunities in Chemistry and Biology. Chem. Asian J. 4 (5), 630-640. doi:10.1002/asia.200800427

Chen, Q., Yang, R., Korolev, N., Liu, C. F., and Nordenskiöld, L. (2017). Regulation of Nucleosome Stacking and Chromatin Compaction by the Histone
H4 N-Terminal Tail-H2a Acidic Patch Interaction. J. Mol. Biol. 429 (13), 2075-2092. doi:10.1016/j.jmb.2017.03.016

Cheutin, T. (2003). Maintenance of Stable Heterochromatin Domains by Dynamic HP1 Binding. Science 299 (5607), 721-725. doi:10.1126/science.1078572

Chodaparambil, J. V., Barbera, A. J., Lu, X., Kaye, K. M., Hansen, J. C., and Luger, K. (2007). A Charged and Contoured Surface on the Nucleosome Regulates Chromatin Compaction. Nat. Struct. Mol. Biol. 14 (11), 1105-1107. doi:10.1038/nsmb1334

Ciragan, A., Backlund, S. M., Mikula, K. M., Beyer, H. M., Samuli Ollila, O. H., and Iwaï, H. (2020). NMR Structure and Dynamics of TonB Investigated by ScarLess Segmental Isotopic Labeling Using a Salt-Inducible Split Intein. Front. Chem. 8, 136. doi:10.3389/fchem.2020.00136

Dann, G. P., Liszczak, G. P., Bagert, J. D., Müller, M. M., Nguyen, U. T. T., Wojcik, F., et al. (2017). ISWI Chromatin Remodellers Sense Nucleosome Modifications to Determine Substrate Preference. Nature 548 (7669), 607-611. doi:10.1038/ nature23671

Davey, C. A., Sargent, D. F., Luger, K., Maeder, A. W., and Richmond, T. J. (2002). Solvent Mediated Interactions in the Structure of the Nucleosome Core Particle

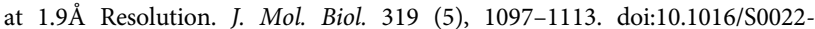
2836(02)00386-8

Dawson, P. E., and Kent, S. B. H. (2000). Synthesis of Native Proteins by Chemical Ligation. Annu. Rev. Biochem. 69 (1), 923-960. doi:10.1146/ annurev.biochem.69.1.923

Debelouchina, G. T., and Muir, T. W. (2017). A Molecular Engineering Toolbox for the Structural Biologist. Quart. Rev. Biophys. 50, e7. doi:10.1017/ S0033583517000051

Dorigo, B., Schalch, T., Bystricky, K., and Richmond, T. J. (2003). Chromatin Fiber Folding: Requirement for the Histone H4 N-Terminal Tail. J. Mol. Biol. 327 (1), 85-96. doi:10.1016/S0022-2836(03)00025-1

Dyer, P. N., Edayathumangalam, R. S., White, C. L., Bao, Y., Chakravarthy, S., Muthurajan, U. M., et al. (2003). "Reconstitution of Nucleosome Core Particles from Recombinant Histones and DNA," in Methods in Enzymology (New York, NY: Elsevier), 23-44. doi:10.1016/s0076-6879(03)75002-2

Farr, S. E., Woods, E. J., Joseph, J. A., Garaizar, A., and Collepardo-Guevara, R. (2021). Nucleosome Plasticity Is a Critical Element of Chromatin Liquid-Liquid Phase Separation and Multivalent Nucleosome Interactions. Nat. Commun. 12 (1), 2883. doi:10.1038/s41467-021-23090-3

Fenley, A. T., Anandakrishnan, R., Kidane, Y. H., and Onufriev, A. V. (2018). Modulation of Nucleosomal DNA Accessibility via Charge-Altering posttranslational Modifications in Histone Core. Epigenetics \& Chromatin 11 (1), 11. doi:10.1186/s13072-018-0181-5

Fierz, B., and Muir, T. W. (2012). Chromatin as an Expansive Canvas for Chemical Biology. Nat. Chem. Biol. 8 (5), 417-427. doi:10.1038/nchembio.938

Fierz, B., and Poirier, M. G. (2019). Biophysics of Chromatin Dynamics. Annu. Rev. Biophys. 48 (1), 321-345. doi:10.1146/annurev-biophys-070317-032847

Fragai, M., Luchinat, C., Parigi, G., and Ravera, E. (2013). Practical Considerations over Spectral Quality in Solid State NMR Spectroscopy of Soluble Proteins. J. Biomol. NMR 57 (2), 155-166. doi:10.1007/s10858-013-9776-0

Frederick, K. K., Michaelis, V. K., Caporini, M. A., Andreas, L. B., Debelouchina, G. T., Griffin, R. G., et al. (2017). Combining DNP NMR with Segmental and Specific Labeling to Study a Yeast Prion Protein Strain that Is Not Parallel InRegister. Proc. Natl. Acad. Sci. USA 114 (14), 3642-3647. doi:10.1073/ pnas. 1619051114

Fyodorov, D. V., and Kadonaga, J. T. (2003). "Chromatin Assembly In Vitro with Purified Recombinant ACF and NAP-1," in Methods in Enzymology (New York, NY: Elsevier), 499-515. doi:10.1016/s0076-6879(03)71037-4

Gao, M., Nadaud, P. S., Bernier, M. W., North, J. A., Hammel, P. C., Poirier, M. G., et al. (2013). Histone H3 and H4 N-Terminal Tails in Nucleosome Arrays at Cellular Concentrations Probed by Magic Angle Spinning NMR Spectroscopy. J. Am. Chem. Soc. 135 (41), 15278-15281. doi:10.1021/ja407526s

Gibson, B. A., Doolittle, L. K., Schneider, M. W. G., Jensen, L. E., Gamarra, N., Henry, L., et al. (2019). Organization of Chromatin by Intrinsic and Regulated Phase Separation. Cell 179 (2), 470-484.e421. doi:10.1016/j.cell.2019.08.037

Gupta, S., and Tycko, R. (2018). Segmental Isotopic Labeling of HIV-1 Capsid Protein Assemblies for Solid State NMR. J. Biomol. NMR 70 (2), 103-114. doi:10.1007/s10858-017-0162-1

Hackeng, T. M., Griffin, J. H., and Dawson, P. E. (1999). Protein Synthesis by Native Chemical Ligation: Expanded Scope by Using Straightforward 
Methodology. Proc. Natl. Acad. Sci. 96 (18), 10068-10073. doi:10.1073/ pnas.96.18.10068

Hancock, R. (2018). Crowding, Entropic Forces, and Confinement: Crucial Factors for Structures and Functions in the Cell Nucleus. Biochem. Mosc. 83 (4), 326-337. doi:10.1134/S0006297918040041

Hartmann, S. R., and Hahn, E. L. (1962). Nuclear Double Resonance in the Rotating Frame. Phys. Rev. 128(5), 2042-2053. doi:10.1103/PhysRev.128.2042

Hassan, A., Quinn, C. M., Struppe, J., Sergeyev, I. V., Zhang, C., Guo, C., et al. (2020). Sensitivity Boosts by the CPMAS CryoProbe for Challenging Biological Assemblies. J. Magn. Reson. 311, 106680. doi:10.1016/j.jmr.2019.106680

He, S., Wu, Z., Tian, Y., Yu, Z., Yu, J., Wang, X., et al. (2020). Structure of Nucleosome-Bound Human BAF Complex. Science 367 (6480), 875-881. doi:10.1126/science.aaz9761

Hihara, S., Pack, C.-G., Kaizu, K., Tani, T., Hanafusa, T., Nozaki, T., et al. (2012). Local Nucleosome Dynamics Facilitate Chromatin Accessibility in Living Mammalian Cells. Cel Rep. 2 (6), 1645-1656. doi:10.1016/j.celrep.2012.11.008

Hsieh, T.-H. S., Weiner, A., Lajoie, B., Dekker, J., Friedman, N., and Rando, O. J. (2015). Mapping Nucleosome Resolution Chromosome Folding in Yeast by Micro-C. Cell 162 (1), 108-119. doi:10.1016/j.cell.2015.05.048

Huynh, V. A. T., Robinson, P. J. J., and Rhodes, D. (2005). A Method for the In Vitro Reconstitution of a Defined "30nm" Chromatin Fibre Containing Stoichiometric Amounts of the Linker Histone. J. Mol. Biol. 345 (5), 957-968. doi:10.1016/j.jmb.2004.10.075

Imai, R., Nozaki, T., Tani, T., Kaizu, K., Hibino, K., Ide, S., et al. (2017). Density Imaging of Heterochromatin in Live Cells Using Orientation-Independent-DIC Microscopy. MBoC 28 (23), 3349-3359. doi:10.1091/mbc.e17-06-0359

Iwai, H., and Züger, S. (2007). Protein Ligation: Applications in NMR Studies of Proteins. Biotechnol. Genet. Eng. Rev. 24 (1), 129-146. doi:10.1080/ 02648725.2007.10648096

Jang, S., and Song, J.-J. (2019). The Big Picture of Chromatin Biology by Cryo-EM. Curr. Opin. Struct. Biol. 58, 76-87. doi:10.1016/j.sbi.2019.05.017

Kalashnikova, A. A., Porter-Goff, M. E., Muthurajan, U. M., Luger, K., and Hansen, J. C. (2013). The Role of the Nucleosome Acidic Patch in Modulating Higher Order Chromatin Structure. J. R. Soc. Interf. 10 (82), 20121022. doi:10.1098/ rsif.2012.1022

Kantidze, O. L., and Razin, S. V. (2020). Weak Interactions in Higher-Order Chromatin Organization. Nucleic Acids Res. 48 (9), 4614-4626. doi:10.1093/ nar/gkaa261

Kato, H., Gruschus, J., Ghirlando, R., Tjandra, N., and Bai, Y. (2009). Characterization of the N-Terminal Tail Domain of Histone H3 in Condensed Nucleosome Arrays by Hydrogen Exchange and NMR. J. Am. Chem. Soc. 131 (42), 15104-15105. doi:10.1021/ja9070078

Kato, H., van Ingen, H., Zhou, B.-R., Feng, H., Bustin, M., Kay, L. E., et al. (2011). Architecture of the High Mobility Group Nucleosomal Protein 2-nucleosome Complex as Revealed by Methyl-Based NMR. Proc. Natl. Acad. Sci. 108 (30), 12283-12288. doi:10.1073/pnas.1105848108

Khanna, N., Zhang, Y., Lucas, J. S., Dudko, O. K., and Murre, C. (2019). Chromosome Dynamics Near the Sol-Gel Phase Transition Dictate the Timing of Remote Genomic Interactions. Nat. Commun. 10 (1), 2771. doi:10.1038/s41467-019-10628-9

Kilic, S., Felekyan, S., Doroshenko, O., Boichenko, I., Dimura, M., Vardanyan, H., et al. (2018). Single-molecule FRET Reveals Multiscale Chromatin Dynamics Modulated by HP1a. Nat. Commun. 9 (1), 235. doi:10.1038/s41467-01702619-5

Kim, K., and Guck, J. (2020). The Relative Densities of Cytoplasm and Nuclear Compartments Are Robust against Strong Perturbation. Biophysical J. 119 (10), 1946-1957. doi:10.1016/j.bpj.2020.08.044

Kitevski-LeBlanc, J. L., Yuwen, T., Dyer, P. N., Rudolph, J., Luger, K., and Kay, L. E. (2018). Investigating the Dynamics of Destabilized Nucleosomes Using MethylTROSY NMR. J. Am. Chem. Soc. 140 (14), 4774-4777. doi:10.1021/ jacs.8b00931

Kouzarides, T. (2007). Chromatin Modifications and Their Function. Cell 128 (4), 693-705. doi:10.1016/j.cell.2007.02.005

Krietenstein, N., Abraham, S., Venev, S. V., Abdennur, N., Gibcus, J., Hsieh, T.-H. S., et al. (2020). Ultrastructural Details of Mammalian Chromosome Architecture. Mol. Cel 78 (3), 554-565.e7. doi:10.1016/j.molcel.2020.03.003
Kwon, B., Tietze, D., White, P. B., Liao, S. Y., and Hong, M. (2015). Chemical Ligation of the Influenza M2 Protein for Solid-State NMR Characterization of the Cytoplasmic Domain. Protein Sci. 24 (7), 1087-1099. doi:10.1002/pro.2690

Lang, K., and Chin, J. W. (2014). Cellular Incorporation of Unnatural Amino Acids and Bioorthogonal Labeling of Proteins. Chem. Rev. 114 (9), 4764-4806. doi: $10.1021 /$ cr400355w

Larson, A. G., Elnatan, D., Keenen, M. M., Trnka, M. J., Johnston, J. B., Burlingame, A. L., et al. (2017). Liquid Droplet Formation by HP1 $\alpha$ Suggests a Role for Phase Separation in Heterochromatin. Nature 547 (7662), 236-240. doi:10.1038/ nature 22822

le Paige, U. B., Xiang, S., Hendrix, M. M. R. M., Zhang, Y., Folkers, G. E., Weingarth, M., et al. (2021). Characterization of Nucleosome Sediments for Protein Interaction Studies by Solid-State NMR Spectroscopy. Magn. Reson. 2 (1), 187-202. doi:10.5194/mr-2-187-2021

Lewandowski, J. R. (2013). Advances in Solid-State Relaxation Methodology for Probing Site-specific Protein Dynamics. Acc. Chem. Res. 46 (9), 2018-2027. doi:10.1021/ar300334g

Lilly Thankamony, A. S., Wittmann, J. J., Kaushik, M., and Corzilius, B. (2017). Dynamic Nuclear Polarization for Sensitivity Enhancement in Modern SolidState NMR. Prog. Nucl. Magn. Reson. Spectrosc. 102-103, 120-195. doi:10.1016/ j.pnmrs.2017.06.002

Lim, B. J., Ackermann, B. E., and Debelouchina, G. T. (2020). Targetable TetrazineBased Dynamic Nuclear Polarization Agents for Biological Systems. ChemBioChem 21 (9), 1315-1319. doi:10.1002/cbic.201900609

Liu, C. C., and Schultz, P. G. (2010). Adding New Chemistries to the Genetic Code. Annu. Rev. Biochem. 79 (1), 413-444. doi:10.1146/annurev.biochem.052308.105824

Lowary, P. T., and Widom, J. (1998). New DNA Sequence Rules for High Affinity Binding to Histone Octamer and Sequence-Directed Nucleosome Positioning. J. Mol. Biol. 276 (1), 19-42. doi:10.1006/jmbi.1997.1494

Lu, X., Simon, M. D., Chodaparambil, J. V., Hansen, J. C., Shokat, K. M., and Luger, K. (2008). The Effect of H3K79 Dimethylation and H4K20 Trimethylation on Nucleosome and Chromatin Structure. Nat. Struct. Mol. Biol. 15 (10), 1122-1124. doi:10.1038/nsmb.1489

Luger, K., Mäder, A. W., Richmond, R. K., Sargent, D. F., and Richmond, T. J. (1997). Crystal Structure of the Nucleosome Core Particle at 2.8 A Resolution. Nature 389 (6648), 251-260. doi:10.1038/38444

Luger, K., Dechassa, M. L., and Tremethick, D. J. (2012). New Insights into Nucleosome and Chromatin Structure: an Ordered State or a Disordered Affair? Nat. Rev. Mol. Cel Biol 13 (7), 436-447. doi:10.1038/nrm3382

Machida, S., Takizawa, Y., Ishimaru, M., Sugita, Y., Sekine, S., Nakayama, J.-i., et al. (2018). Structural Basis of Heterochromatin Formation by Human HP1. Mol. Cel 69 (3), 385-397.e8. doi:10.1016/j.molcel.2017.12.011

Maeshima, K., Matsuda, T., Shindo, Y., Imamura, H., Tamura, S., Imai, R., et al. (2018). A Transient Rise in Free Mg2+ Ions Released from ATP-Mg Hydrolysis Contributes to Mitotic Chromosome Condensation. Curr. Biol. 28 (3), 444-451.e6. doi:10.1016/j.cub.2017.12.035

Maeshima, K., Ide, S., and Babokhov, M. (2019). Dynamic Chromatin Organization without the 30-nm Fiber. Curr. Opin. Cel Biol. 58, 95-104. doi:10.1016/j.ceb.2019.02.003

Mandal, A., Boatz, J. C., Wheeler, T. B., and van der Wel, P. C. A. (2017). On the Use of Ultracentrifugal Devices for Routine Sample Preparation in Biomolecular Magic-Angle-Spinning NMR. J. Biomol. NMR 67 (3), 165-178. doi:10.1007/s10858-017-0089-6

Mashtalir, N., Suzuki, H., Farrell, D. P., Sankar, A., Luo, J., Filipovski, M., et al. (2020). A Structural Model of the Endogenous Human BAF Complex Informs Disease Mechanisms. Cell 183 (3), 802-817.e24. doi:10.1016/j.cell.2020.09.051

Matlahov, I., and van der Wel, P. C. A. (2018). Hidden Motions and MotionInduced Invisibility: Dynamics-Based Spectral Editing in Solid-State NMR. Methods 148, 123-135. doi:10.1016/j.ymeth.2018.04.015

McGinty, R. K., and Tan, S. (2021). Principles of Nucleosome Recognition by Chromatin Factors and Enzymes. Curr. Opin. Struct. Biol. 71, 16-26. doi:10.1016/j.sbi.2021.05.006

McGinty, R. K., Makde, R. D., and Tan, S. (2016). "Preparation, Crystallization, and Structure Determination of Chromatin Enzyme/Nucleosome Complexes," in Methods in Enzymology (New York, NY: Elsevier), 43-65. doi:10.1016/ bs.mie.2016.01.003 
Min, J., and Liu, K. (2021). Structures of Chromatin Modulators in Complex with Nucleosome. Curr. Opin. Chem. Biol. 63, 105-114. doi:10.1016/ j.cbpa.2021.02.018

Mishra, L. N., Pepenella, S., Rogge, R., Hansen, J. C., and Hayes, J. J. (2016). Acetylation Mimics within a Single Nucleosome Alter Local DNA Accessibility in Compacted Nucleosome Arrays. Sci. Rep. 6 (1), 34808. doi:10.1038/ srep34808

Morris, G. A., and Freeman, R. (1979). Enhancement of Nuclear Magnetic Resonance Signals by Polarization Transfer. J. Am. Chem. Soc. 101(3), 760-762. doi:10.1021/ja00497a058

Morrison, E. A., Baweja, L., Poirier, M. G., Wereszczynski, J., and Musselman, C. A. (2021). Nucleosome Composition Regulates the Histone H3 Tail Conformational Ensemble and Accessibility. Nucleic Acids Res. 49 (8), 4750-4767. doi:10.1093/nar/gkab246

Müller, M. M., and Muir, T. W. (2015). Histones: At the Crossroads of Peptide and Protein Chemistry. Chem. Rev. 115 (6), 2296-2349. doi:10.1021/cr5003529

Muir, T. W., Sondhi, D., and Cole, P. A. (1998). Expressed Protein Ligation: A General Method for Protein Engineering. Proc. Natl. Acad. Sci. 95 (12), 6705-6710. doi:10.1073/pnas.95.12.6705

Müller, M. M., Fierz, B., Bittova, L., Liszczak, G., and Muir, T. W. (2016). A TwoState Activation Mechanism Controls the Histone Methyltransferase Suv39h1. Nat. Chem. Biol. 12 (3), 188-193. doi:10.1038/nchembio.2008

Munowitz, M., Aue, W. P., and Griffin, R. G. (1982). Two-dimensional Separation of Dipolar and Scaled Isotropic Chemical Shift Interactions in Magic Angle NMR Spectra. J. Chem. Phys. 77 (4), 1686-1689. doi:10.1063/1.444064

Neumann, H., Peak-Chew, S. Y., and Chin, J. W. (2008). Genetically Encoding NeAcetyllysine in Recombinant Proteins. Nat. Chem. Biol. 4 (4), 232-234. doi:10.1038/nchembio.73

Nguyen, U. T. T., Bittova, L., Müller, M. M., Fierz, B., David, Y., Houck-Loomis, B., et al. (2014). Accelerated Chromatin Biochemistry Using DNA-Barcoded Nucleosome Libraries. Nat. Methods 11 (8), 834-840. doi:10.1038/nmeth.3022

Nozaki, T., Imai, R., Tanbo, M., Nagashima, R., Tamura, S., Tani, T., et al. (2017). Dynamic Organization of Chromatin Domains Revealed by Super-resolution Live-Cell Imaging. Mol. Cel 67 (2), 282-293.e7. doi:10.1016/ j.molcel.2017.06.018

Ohno, M., Ando, T., Priest, D. G., Kumar, V., Yoshida, Y., and Taniguchi, Y. (2019). Sub-nucleosomal Genome Structure Reveals Distinct Nucleosome Folding Motifs. Cell 176 (3), 520-534.e25. doi:10.1016/j.cell.2018.12.014

Otterstrom, J., Castells-Garcia, A., Vicario, C., Gomez-Garcia, P. A., Cosma, M. P., and Lakadamyali, M. (2019). Super-resolution Microscopy Reveals How Histone Tail Acetylation Affects DNA Compaction within Nucleosomes In Vivo. Nucleic Acids Res. 47 (16), 8470-8484. doi:10.1093/nar/gkz593

Ou, H. D., Phan, S., Deerinck, T. J., Thor, A., Ellisman, M. H., and O'Shea, C. C. (2017). ChromEMT: Visualizing 3D Chromatin Structure and Compaction in Interphase and Mitotic Cells. Science 357 (6349), eaag0025. doi:10.1126/ science.aag0025

Peng, Y., Li, S., Landsman, D., and Panchenko, A. R. (2021). Histone Tails as Signaling Antennas of Chromatin. Curr. Opin. Struct. Biol. 67, 153-160. doi:10.1016/j.sbi.2020.10.018

Pines, A., Gibby, M. G., and Waugh, J. S. (1973). Proton-Enhanced NMR of Dilute Spins in Solids. J. Chem. Phys. 59(2), 569-590. doi:10.1063/1.1680061

Pinto, F., Thornton, E. L., and Wang, B. (2020). An Expanded Library of Orthogonal Split Inteins Enables Modular Multi-Peptide Assemblies. Nat. Commun. 11 (1). doi:10.1038/s41467-020-15272-2

Pirman, N. L., Barber, K. W., Aerni, H. R., Ma, N. J., Haimovich, A. D., Rogulina, S., et al. (2015). A Flexible Codon in Genomically Recoded Escherichia coli Permits Programmable Protein Phosphorylation. Nat. Commun. 6, 8130. doi:10.1038/ ncomms 9130

Poepsel, S., Kasinath, V., and Nogales, E. (2018). Cryo-EM Structures of PRC2 Simultaneously Engaged with Two Functionally Distinct Nucleosomes. Nat. Struct. Mol. Biol. 25 (2), 154-162. doi:10.1038/s41594-018-0023-y

Poirier, M. G., Oh, E., Tims, H. S., and Widom, J. (2009). Dynamics and Function of Compact Nucleosome Arrays. Nat. Struct. Mol. Biol. 16 (9), 938-944. doi:10.1038/nsmb.1650

Prakash, K., and Fournier, D. (2017). Histone Code and Higher-Order Chromatin Folding: A Hypothesis. Genomics Comput. Biol. 3 (2), 41. doi:10.18547/ gcb.2017.vol3.iss2.e41
Quinn, C. M., and Polenova, T. (2017). Structural Biology of Supramolecular Assemblies by Magic-Angle Spinning NMR Spectroscopy. Quart. Rev. Biophys. 50, e1. doi:10.1017/S0033583516000159

Rabdano, S. O., Shannon, M. D., Izmailov, S. A., Gonzalez Salguero, N., Zandian, M., Purusottam, R. N., et al. (2021). Histone H4 Tails in Nucleosomes: a Fuzzy Interaction with DNA. Angew. Chem. Int. Ed. 60 (12), 6480-6487. doi:10.1002/ anie. 202012046

Rao, S. S. P., Huntley, M. H., Durand, N. C., Stamenova, E. K., Bochkov, I. D., Robinson, J. T., et al. (2014). A 3D Map of the Human Genome at Kilobase Resolution Reveals Principles of Chromatin Looping. Cell 159 (7), 1665-1680. doi:10.1016/j.cell.2014.11.021

Ricci, M. A., Manzo, C., García-Parajo, M. F., Lakadamyali, M., and Cosma, M. P. (2015). Chromatin Fibers Are Formed by Heterogeneous Groups of Nucleosomes In Vivo. Cell 160 (6), 1145-1158. doi:10.1016/j.cell.2015.01.054

Risca, V. I., Denny, S. K., Straight, A. F., and Greenleaf, W. J. (2017). Variable Chromatin Structure Revealed by In Situ Spatially Correlated DNA Cleavage Mapping. Nature 541 (7636), 237-241. doi:10.1038/nature20781

Sanulli, S., Trnka, M. J., Dharmarajan, V., Tibble, R. W., Pascal, B. D., Burlingame, A. L., et al. (2019). HP1 Reshapes Nucleosome Core to Promote Phase Separation of Heterochromatin. Nature 575 (7782), 390-394. doi:10.1038/ s41586-019-1669-2

Schubeis, T., Lührs, T., and Ritter, C. (2015). Unambiguous Assignment of Shortand Long-Range Structural Restraints by Solid-State NMR Spectroscopy with Segmental Isotope Labeling. ChemBioChem 16 (1), 51-54. doi:10.1002/ cbic. 201402446

Shah, N. H., and Muir, T. W. (2014). Inteins: Nature's Gift to Protein Chemists. Chem. Sci. 5 (2), 446-461. doi:10.1039/C3SC52951G

Shi, X., Prasanna, C., Nagashima, T., Yamazaki, T., Pervushin, K., and Nordenskiöld, L. (2018). Structure and Dynamics in the Nucleosome Revealed by Solid-State NMR. Angew. Chem. Int. Ed. 57 (31), 9734-9738. doi:10.1002/anie.201804707

Shi, X., Prasanna, C., Pervushin, K., and Nordenskiöld, L. (2020a). Solid-state NMR 13C, $15 \mathrm{~N}$ Assignments of Human Histone H3 in the Nucleosome Core Particle. Biomol. NMR Assign 14 (1), 99-104. doi:10.1007/s12104-020-09927-w

Shi, X., Prasanna, C., Soman, A., Pervushin, K., and Nordenskiöld, L. (2020b). Dynamic Networks Observed in the Nucleosome Core Particles Couple the Histone Globular Domains with DNA. Commun. Biol. 3 (1), 639. doi:10.1038/ s42003-020-01369-3

Shoaib, M., Chen, Q., Shi, X., Nair, N., Prasanna, C., Yang, R., et al. (2021). Histone H4 Lysine 20 Mono-Methylation Directly Facilitates Chromatin Openness and Promotes Transcription of Housekeeping Genes. Nat. Commun. 12 (1), 4800. doi:10.1038/s41467-021-25051-2

Shogren-Knaak, M. (2006). Histone H4-K16 Acetylation Controls Chromatin Structure and Protein Interactions. Science 311 (5762), 844-847. doi:10.1126/science. 1124000

Simon, M. D., Chu, F., Racki, L. R., de la Cruz, C. C., Burlingame, A. L., Panning, B., et al. (2007). The Site-specific Installation of Methyl-Lysine Analogs into Recombinant Histones. Cell 128 (5), 1003-1012. doi:10.1016/ j.cell.2006.12.041

Simpson, R. T., Thoma, F., and Brubaker, J. M. (1985). Chromatin Reconstituted from Tandemly Repeated Cloned DNA Fragments and Core Histones: A Model System for Study of Higher Order Structure. Cell 42 (3), 799-808. doi:10.1016/ 0092-8674(85)90276-4

Sinha, K. K., Gross, J. D., and Narlikar, G. J. (2017). Distortion of Histone Octamer Core Promotes Nucleosome Mobilization by a Chromatin Remodeler. Science 355 (6322), eaaa3761. doi:10.1126/science.aaa3761

Soman, A., Liew, C. W., Teo, H. L., Berezhnoy, N. V., Olieric, V., Korolev, N., et al. (2020). The Human Telomeric Nucleosome Displays Distinct Structural and Dynamic Properties. Nucleic Acids Res. 48 (10), 5383-5396. doi:10.1093/nar/ gkaa289

Stevens, A. J., Brown, Z. Z., Shah, N. H., Sekar, G., Cowburn, D., and Muir, T. W. (2016). Design of a Split Intein with Exceptional Protein Splicing Activity. J. Am. Chem. Soc. 138 (7), 2162-2165. doi:10.1021/jacs.5b13528

Strickfaden, H., Tolsma, T. O., Sharma, A., Underhill, D. A., Hansen, J. C., and Hendzel, M. J. (2020). Condensed Chromatin Behaves like a Solid on the Mesoscale In Vitro and in Living Cells. Cell 183 (7), 1772-1784.e13. doi:10.1016/j.cell.2020.11.027 
Strom, A. R., Biggs, R. J., Banigan, E. J., Wang, X., Chiu, K., Herman, C., et al. (2021). HP1a Is a Chromatin Crosslinker that Controls Nuclear and Mitotic Chromosome Mechanics. Elife 10, e63972. doi:10.7554/eLife.63972

Struppe, J., Quinn, C. M., Lu, M., Wang, M., Hou, G., Lu, X., et al. (2017). Expanding the Horizons for Structural Analysis of Fully Protonated Protein Assemblies by NMR Spectroscopy at MAS Frequencies above $100 \mathrm{kHz}$. Solid State. Nucl. Magn. Reson. 87, 117-125. doi:10.1016/j.ssnmr.2017.07.001

Stützer, A., Liokatis, S., Kiesel, A., Schwarzer, D., Sprangers, R., Söding, J., et al. (2016). Modulations of DNA Contacts by Linker Histones and Posttranslational Modifications Determine the Mobility and Modifiability of Nucleosomal H3 Tails. Mol. Cel 61 (2), 247-259. doi:10.1016/ j.molcel.2015.12.015

Su, J.-H., Zheng, P., Kinrot, S. S., Bintu, B., and Zhuang, X. (2020). Genome-Scale Imaging of the 3D Organization and Transcriptional Activity of Chromatin. Cell 182 (6), 1641-1659.e26. doi:10.1016/j.cell.2020.07.032

Teles, K., Fernandes, V., Silva, I., Leite, M., Grisolia, C., Lobbia, V. R., et al. (2020). Nucleosome Binding Peptide Presents Laudable Biophysical and In Vivo Effects. Biomed. Pharmacother. 121, 109678. doi:10.1016/j.biopha.2019.109678 van der Wel, P. C. A. (2018). New Applications of Solid-State NMR in Structural Biology. Emerging Top. Life Sci. 2 (1), 57-67. doi:10.1042/ETLS20170088

van Emmerik, C. L., and van Ingen, H. (2019). Unspinning Chromatin: Revealing the Dynamic Nucleosome Landscape by NMR. Prog. Nucl. Magn. Reson. Spectrosc. 110, 1-19. doi:10.1016/j.pnmrs.2019.01.002

Wang, Z. A., and Liu, W. R. (2017). Proteins with Site-Specific Lysine Methylation. Chem. Eur. J. 23 (49), 11732-11737. doi:10.1002/chem.201701655

Weber, A. (2019). Evidence for and against Liquid-Liquid Phase Separation in the Nucleus. ncRNA 5 (4), 50. doi:10.3390/ncrna5040050

Wiegand, T., Cadalbert, R., von Schroetter, C., Allain, F. H.-T., and Meier, B. H. (2018). Segmental Isotope Labelling and Solid-State NMR of a $12 \times 59 \mathrm{kDa}$ Motor Protein: Identification of Structural Variability. J. Biomol. NMR 71 (4), 237-245. doi:10.1007/s10858-018-0196-Z

Wiegand, T., Lacabanne, D., Torosyan, A., Boudet, J., Cadalbert, R., Allain, F. H.T., et al. (2020). Sedimentation Yields Long-Term Stable Protein Samples as Shown by Solid-State NMR. Front. Mol. Biosci. 7, 17. doi:10.3389/ fmolb.2020.00017

Woodcock, C. L. F., Safer, J. P., and Stanchfield, J. E. (1976). Structural Repeating Units in Chromatin. Exp. Cel Res. 97 (1), 101-110. doi:10.1016/0014-4827(76) 90659-5

Xiang, S., le Paige, U. B., Horn, V., Houben, K., Baldus, M., and van Ingen, H. (2018). Site-Specific Studies of Nucleosome Interactions by Solid-State NMR Spectroscopy. Angew. Chem. Int. Ed. 57 (17), 4571-4575. doi:10.1002/ anie. 201713158

Xu, J., Ma, H., Jin, J., Uttam, S., Fu, R., Huang, Y., et al. (2018). Super-Resolution Imaging of Higher-Order Chromatin Structures at Different Epigenomic States in Single Mammalian Cells. Cel Rep. 24 (4), 873-882. doi:10.1016/j.celrep.2018.06.085
Yan, L. Z., and Dawson, P. E. (2001). Synthesis of Peptides and Proteins without Cysteine Residues by Native Chemical Ligation Combined with Desulfurization. J. Am. Chem. Soc. 123 (4), 526-533. doi:10.1021/ja003265m

Yang, J. G., Madrid, T. S., Sevastopoulos, E., and Narlikar, G. J. (2006). The Chromatin-Remodeling Enzyme ACF Is an ATP-dependent DNA Length Sensor that Regulates Nucleosome Spacing. Nat. Struct. Mol. Biol. 13 (12), 1078-1083. doi:10.1038/nsmb1170

Zandian, M., Gonzalez Salguero, N., Shannon, M. D., Purusottam, R. N., Theint, T. Poirier, M. G., et al. (2021). Conformational Dynamics of Histone H3 Tails in Chromatin. J. Phys. Chem. Lett. 12, 6174-6181. doi:10.1021/acs.jpclett.1c01187

Zhou, J., Fan, J. Y., Rangasamy, D., and Tremethick, D. J. (2007). The Nucleosome Surface Regulates Chromatin Compaction and Couples it with Transcriptional Repression. Nat. Struct. Mol. Biol. 14 (11), 1070-1076. doi:10.1038/nsmb1323

Zhou, B.-R., Feng, H., Ghirlando, R., Kato, H., Gruschus, J., and Bai, Y. (2012). Histone H4 K16Q Mutation, an Acetylation Mimic, Causes Structural Disorder of its N-Terminal Basic Patch in the Nucleosome. J. Mol. Biol. 421 (1), 30-37. doi:10.1016/j.jmb.2012.04.032

Zhou, K., Gaullier, G., and Luger, K. (2019). Nucleosome Structure and Dynamics Are Coming of Age. Nat. Struct. Mol. Biol. 26 (1), 3-13. doi:10.1038/s41594018-0166-x

Zoukimian, C., Meudal, H., De Waard, S., Ouares, K. A., Nicolas, S., Canepari, M., et al. (2019). Synthesis by Native Chemical Ligation and Characterization of the Scorpion Toxin AmmTx3. Bioorg. Med. Chem. 27 (1), 247-253. doi:10.1016/ j.bmc.2018.12.009

Züger, S., and Iwai, H. (2005). Intein-based Biosynthetic Incorporation of Unlabeled Protein Tags into Isotopically Labeled Proteins for NMR Studies. Nat. Biotechnol. 23 (6), 736-740. doi:10.1038/nbt1097

Conflict of Interest: The authors declare that the research was conducted in the absence of any commercial or financial relationships that could be construed as a potential conflict of interest.

Publisher's Note: All claims expressed in this article are solely those of the authors and do not necessarily represent those of their affiliated organizations, or those of the publisher, the editors and the reviewers. Any product that may be evaluated in this article, or claim that may be made by its manufacturer, is not guaranteed or endorsed by the publisher.

Copyright (c) 2021 Ackermann and Debelouchina. This is an open-access article distributed under the terms of the Creative Commons Attribution License (CC BY). The use, distribution or reproduction in other forums is permitted, provided the original author(s) and the copyright owner(s) are credited and that the original publication in this journal is cited, in accordance with accepted academic practice. No use, distribution or reproduction is permitted which does not comply with these terms. 